http://jmscr.igmpublication.org/home/ ISSN (e)-2347-176x ISSN (p) 2455-0450 crossref DOI: https://dx.doi.org/10.18535/jmscr/v8i4.52

\title{
Prospective Study on Assessment of Atopy by Serum IgE in Asthma \& Rhinosinusitis
}

\author{
Authors \\ Dr Naresh Kumar Rao $\mathbf{P}^{1}$, Dr Shahzad Hussain Arastu ${ }^{2 *}$ \\ ${ }^{1}$ Post Graduate Student of Pulmonology, Shadan Institute of Medical Science, Hyderabad, India \\ ${ }^{2}$ Asisstant Professor of Pulmonology, Shadan Institute of Medical Science, Hyderabad, India \\ *Corresponding Author \\ Dr Shahzad Hussain Arastu
}

\begin{abstract}
Asthma and allergy often occur together. People with allergic rhinitis, atopic eczema, food allergy and those who have asthma running in the family are at risk of developing asthma. Allergy is the most common cause of triggering asthma.

Bronchial asthma and rhinosinusitis are common respiratory diseases that often coexist. Furthermore and of considerable interest is the possibility that severity of asthma is influenced by the upper airway diseases. The influence and interaction between asthma and rhinitis exist with chronic rhinosinusitis, allergic rhinitis, viral and Bacterial respiratory tract infection. These observations raise the possibility, that events in the upper respiratory tract can influence lower respiratory tract. It's now being appreciated the concept of one airway and one disease, also known as Allergic rhinitis and its impact on asthma (ARIA). We have conducted a study to assess Atopy by measuring serum IgE levels \& esinophils in asthma and rhinosinusitis patients and comparing the two groups.

Keywords: Atopy, Allergic rhinitis, Asthma, Rhinosinusitis, serum IgE, Eosinophils.
\end{abstract}

\section{Introduction}

Atopy is defined as a personal and/or familial tendency, usually in childhood or adolescence, to become sensitized and produce $\operatorname{IgE}$ antibodies in response to ordinary exposures to allergens, usually proteins. As a consequence, these persons can develop typical symptoms of asthma, rhinoconjunctivitis, or eczema. ${ }^{5}$

Asthma is a common, chronic respiratory disease affecting $1-18 \%$ of the population in different countries ${ }^{1}$. Asthma is a heterogeneous disease, usually characterized by chronic airway inflammation. Symptoms and airflow limitation may resolve spontaneously or in response to medication, and sometimes be absent for weeks or months at a time. On the other hand, patients can experience episodic flare-ups (exacerbations) of asthma that may be life-threatening and carry a significant burden to patients and the community. Allergic asthma: this is the most easily recognized asthma phenotype, which often commences in childhood and is associated with a past and/or family history of allergic disease such as eczema, allergic rhinitis, or food or drug allergy.

Rhinosinusitis is characterized if two or more symptoms persist for greater than 12 weeks; symptoms include facial pain/pressure, purulent nasal discharge, nasal obstruction, and decreased 
sense of smell during chronic inflammation confirmed through endoscopy or radiographic studies. It is a heterogeneous disorder comprised of two primary phenotypic presentations, clinically differentiated as either RS with nasal polyposis or RS without nasal polyposis ${ }^{3}$. The indicators for eosinophil chemotaxis and activation, IgE, have been found to be significantly increased in Nasal polyp and Rhinosinusitis ${ }^{4}$.

There is considerable overlap in the symptoms of allergic rhinitis, sinusitis and asthma because of common pathogenesis and the role of eosinophils, Atopy and the concept of one airway one disease. Rhinosinusitis coexists with asthma in $34-50 \%$ of patients ${ }^{7}$.

Stimulating the need to study the role of atopy and serum IgE Levels in these group of patients.

\section{Materials and Methods}

\section{Subjects}

100 patients seeking consultation in Pulmonology Medicine Department, Shadan Institute of Medical Sciences and Hospital from January 2016 to October 2017 were part of the study.

\section{Inclusion Criteria}

Patients suffering from asthma and rhinosinusitis will be included in the study.

\section{Exclusion Criteria}

1. Patients $<15$ years

2. Patients on ANTI IgE THERAPY.

3. Patients unwilling to take part in the study or to give written consent for study.

\section{Methods}

ASTHMA patients diagnosed according to GINA (2017) guidelines.

Investigations like chest X-ray, X -ray PNS, Serum IgE, Spirometry, Absolute Eosinophil count, CT PNS.

The respiratory questionnaires from the AAACI was used for this study.

ELISA method for measuring serum IgE Level.

The test will be considered positive if serum $\mathrm{IgE}>100 \mathrm{IU} / \mathrm{L}$.

\section{Results}

Table 1: Distribution of Diagnosis

\begin{tabular}{|l|c|c|}
\hline DIAGNOSIS & No. of cases & \% of cases \\
\hline ASTHMA & 60 & 60.0 \\
\hline RHINOSINUSITIS & 24 & 24.0 \\
\hline Asthma+Rhinosinusitis & 16 & 16.0 \\
\hline Total & 100 & 100.0 \\
\hline
\end{tabular}

\section{Distribution of Diagnosis}

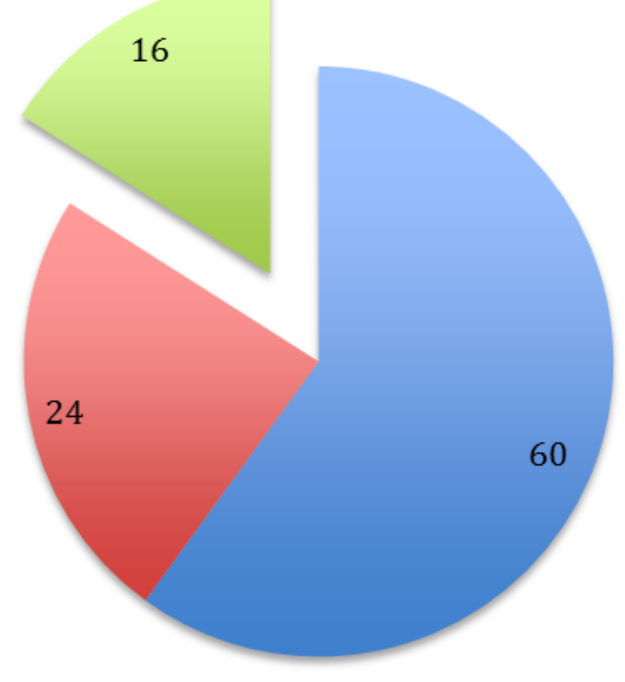

- ASTHMA

- RHINOSINUSITIS

- Asthma+Rhinosinusitis

Of 100 cases studied, 60 cases $(60.0 \%)$ had Asthma, 24 cases $(24.0 \%)$ had Rhinoinusitis and 16 cases (16.0\%) had Asthma +Rhinoinusitis. 


\section{JMSCR Vol||08||Issue ||04||Page 285-291||April}

Table 2: Age wise Distribution Percentage $(n=100)$

\begin{tabular}{|l|c|c|}
\hline AGE & No. of Cases & Percentage of cases \\
\hline $15-20$ & 7 & 7.0 \\
\hline $21-30$ & 20 & 20.0 \\
\hline $31-40$ & 24 & 24.0 \\
\hline $41-50$ & 16 & 16.0 \\
\hline $51-60$ & 19 & 19.0 \\
\hline$>60$ & 14 & 11.0 \\
\hline TOTAL & $\mathbf{1 0 0}$ & $\mathbf{1 0 0 . 0}$ \\
& & \\
& & \\
\hline
\end{tabular}

\section{Age Wise Distribution}

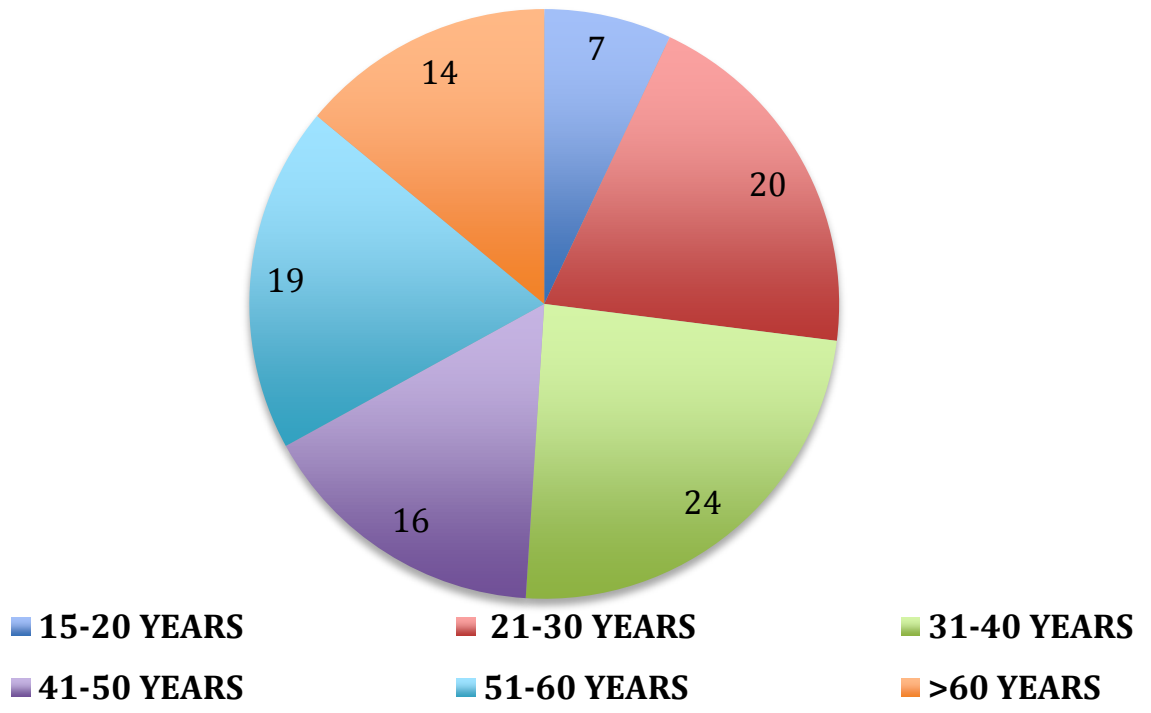

Maximum number of patients are in younger (31-40 year) age group.

Sex wise Distribution of cases studied $(n=100)$

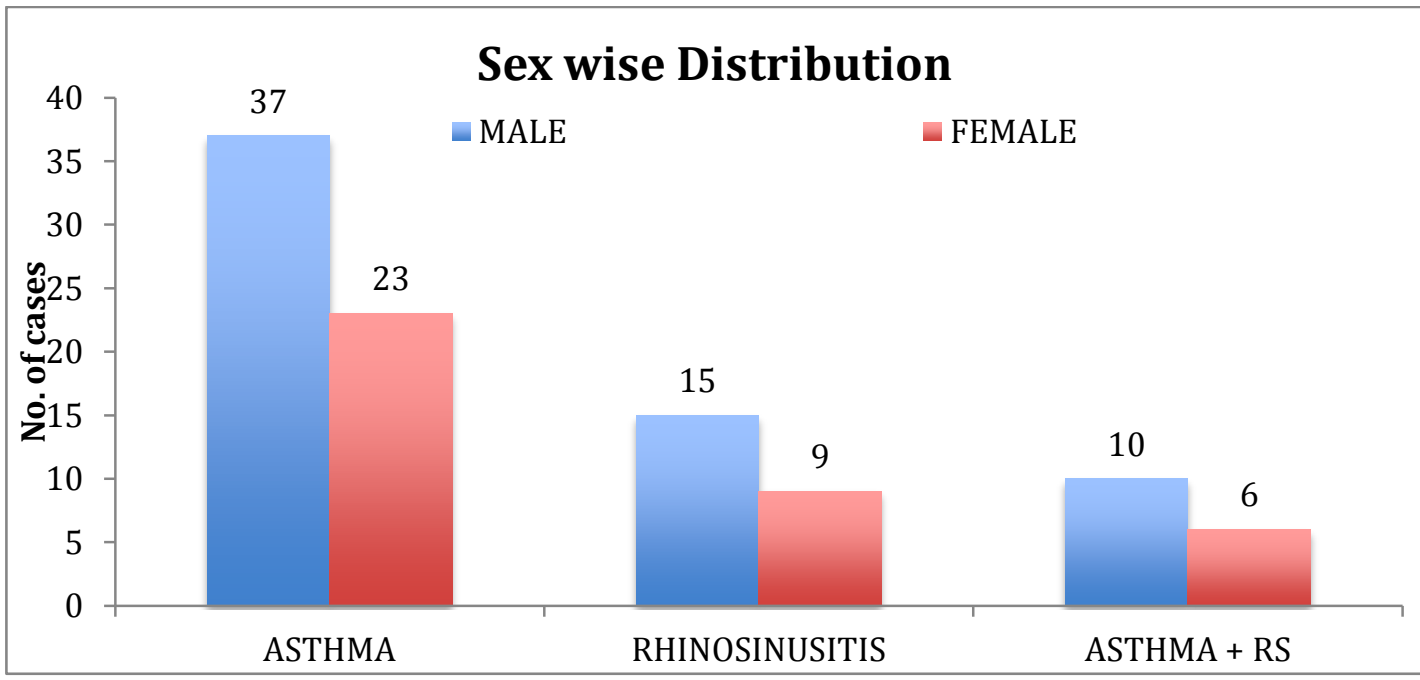

Predominant MALES in all the groups of Asthma, Rhinosinusitis \& Asthma+Rhinosinusitis 


\section{JMSCR Vol||08||Issue||04||Page 285-291||April}

IgE levels: 4

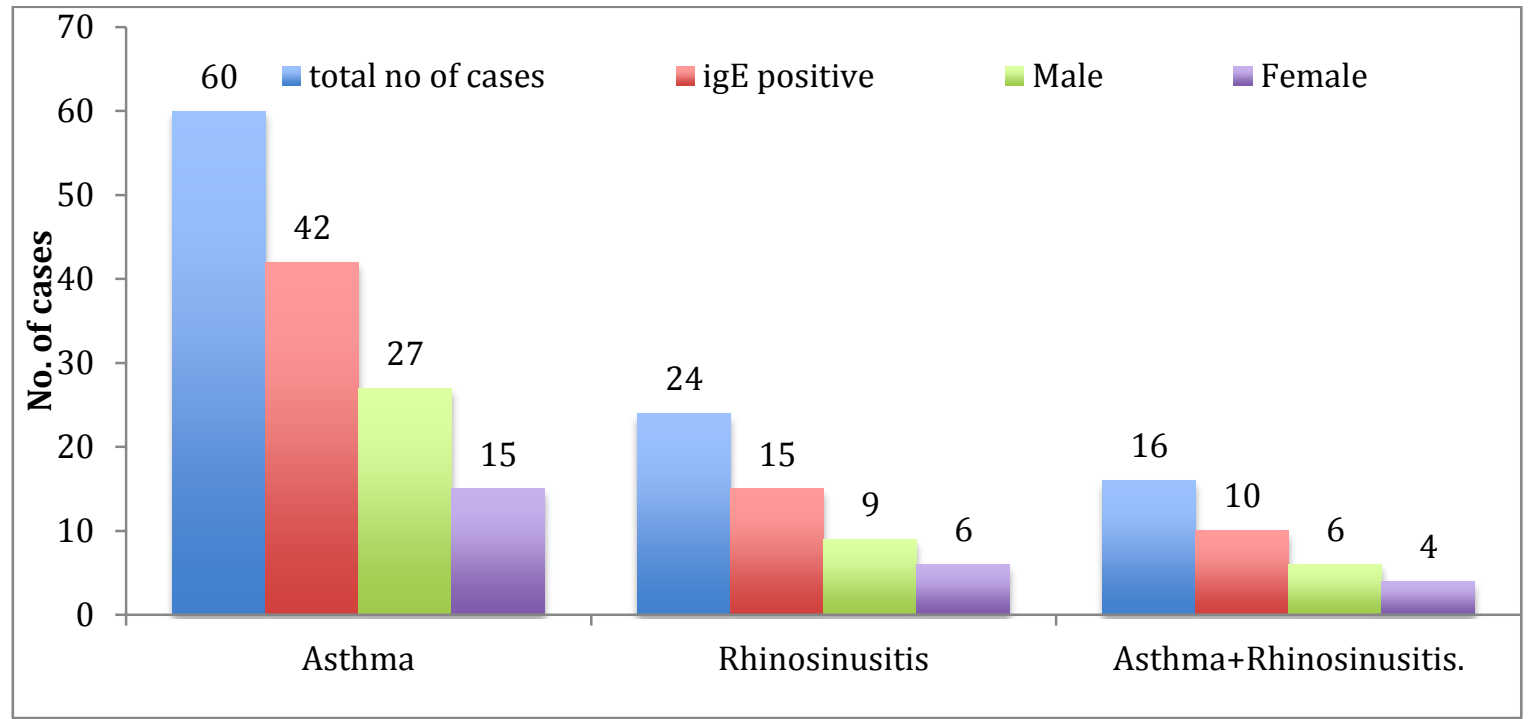

- 70\% (42 out of 60) ASTHMA cases\&

- Elevated IgE LEVELS are more common $62.5 \%$ of rhinosinusitis and asthma+RS in male patients in this study. cases had increased IgE Levels.

Table 5: According to IgE levels cases were divided into 6 Groups.

\begin{tabular}{|c|c|c|c|c|}
\hline & & & \multicolumn{2}{|c|}{ DIAGNOSIS } \\
\hline LEVELS & $\begin{array}{l}\text { TOTAL NO } \\
\text { OF CASES }\end{array}$ & ASTHMA & $\begin{array}{c}\text { RHINOSINUSI } \\
\text { TIS }\end{array}$ & $\mathbf{A + R S}$ \\
\hline NORMAL $(<100)$ & 33 & 18 & 9 & 6 \\
\hline $101-200$ & 15 & 7 & 7 & 1 \\
\hline $201-300$ & 19 & 12 & 5 & 2 \\
\hline $301-400$ & 24 & 19 & 1 & 4 \\
\hline $401-500$ & 6 & 3 & 1 & 2 \\
\hline $501-1000$ & 3 & 1 & 1 & 1 \\
\hline TOTAL & 100 & 60 & 24 & 16 \\
\hline
\end{tabular}

Distribution of IgE levels did not differ significantly across various types of diagnosis $33 \%$ of cases had normal IgE Levels
$67 \%$ of total number of cases had elevated serum Ig E Levels.

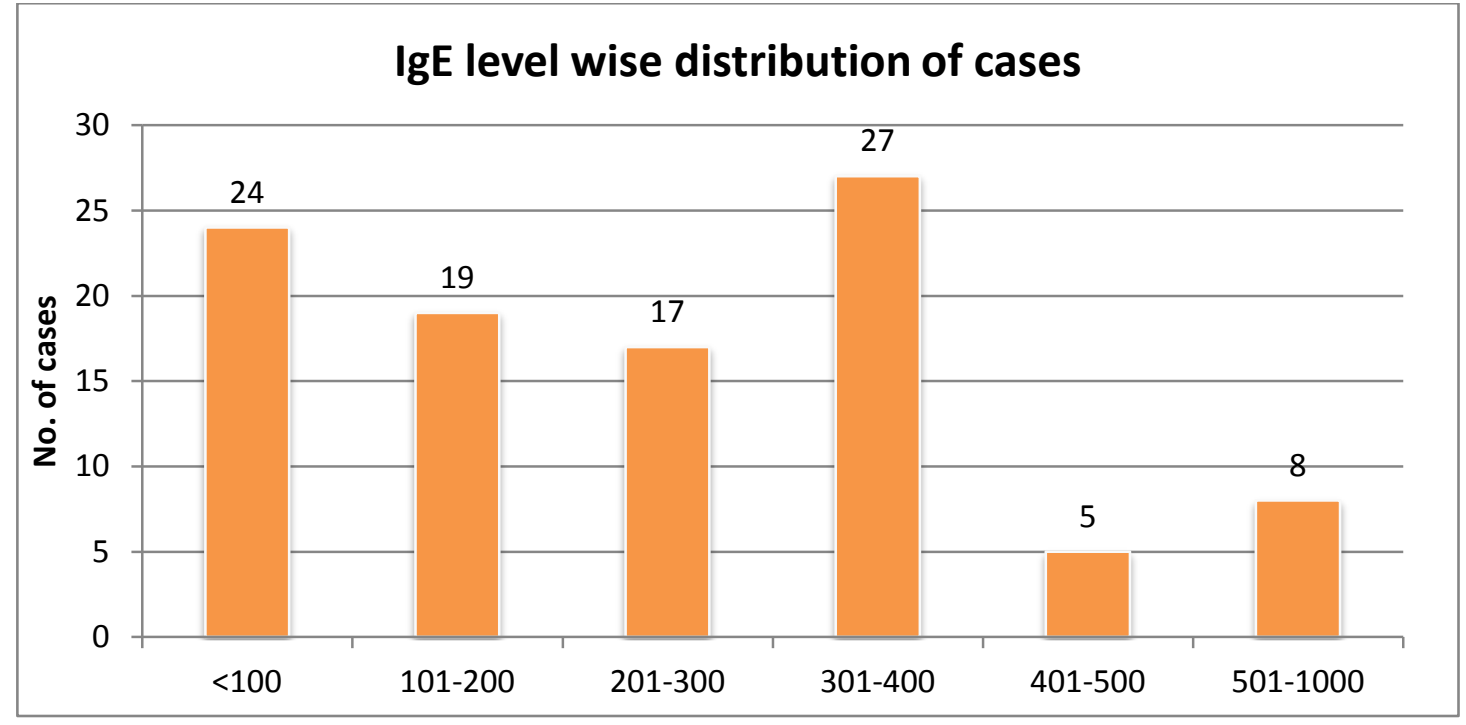




\section{JMSCR Vol||08||Issue||04||Page 285-291||April}

Table no 6: Diagnosis wise distribution of AEC (Absolute Eosinophil Count)

\begin{tabular}{|c|c|c|c|}
\hline DIAGNOSIS & TOTAL no of cases & \multicolumn{2}{|c|}{ ELEVATED AEC } \\
\hline & & $\mathrm{n}$ & $\%$ \\
\hline ASTHMA & 60 & 39 & 65.0 \\
\hline RHINOSINUSITIS & 24 & 9 & 37.5 \\
\hline $\mathrm{A}+\mathrm{RS}$ & 16 & 11 & 68.7 \\
\hline Total & 100 & 59 & 59.0 \\
\hline
\end{tabular}

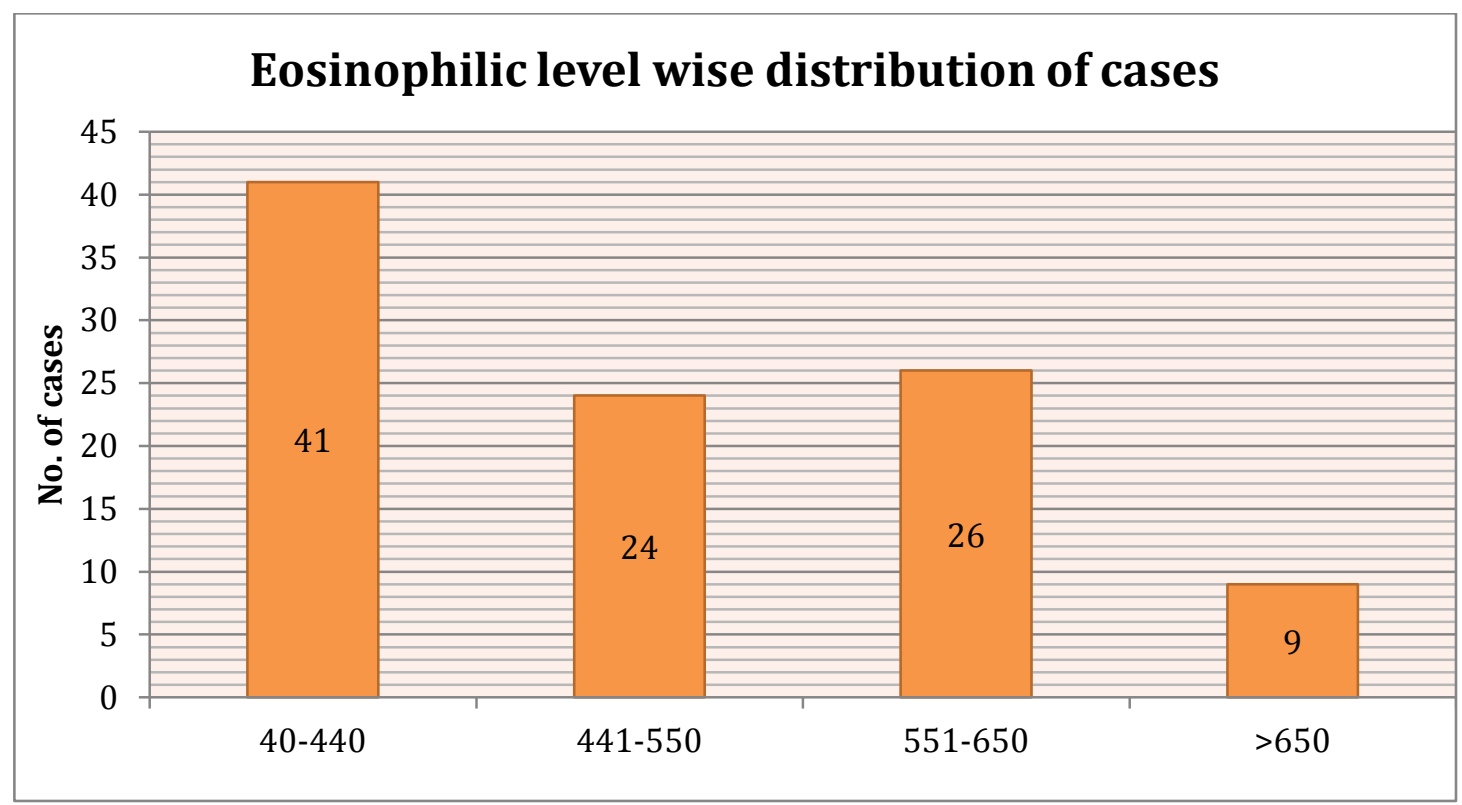

Overall 41\% had normal AEC Levels, Remaining 59\% had elevated eosinophil counts.

Table 7: FEV1 level wise distribution of cases

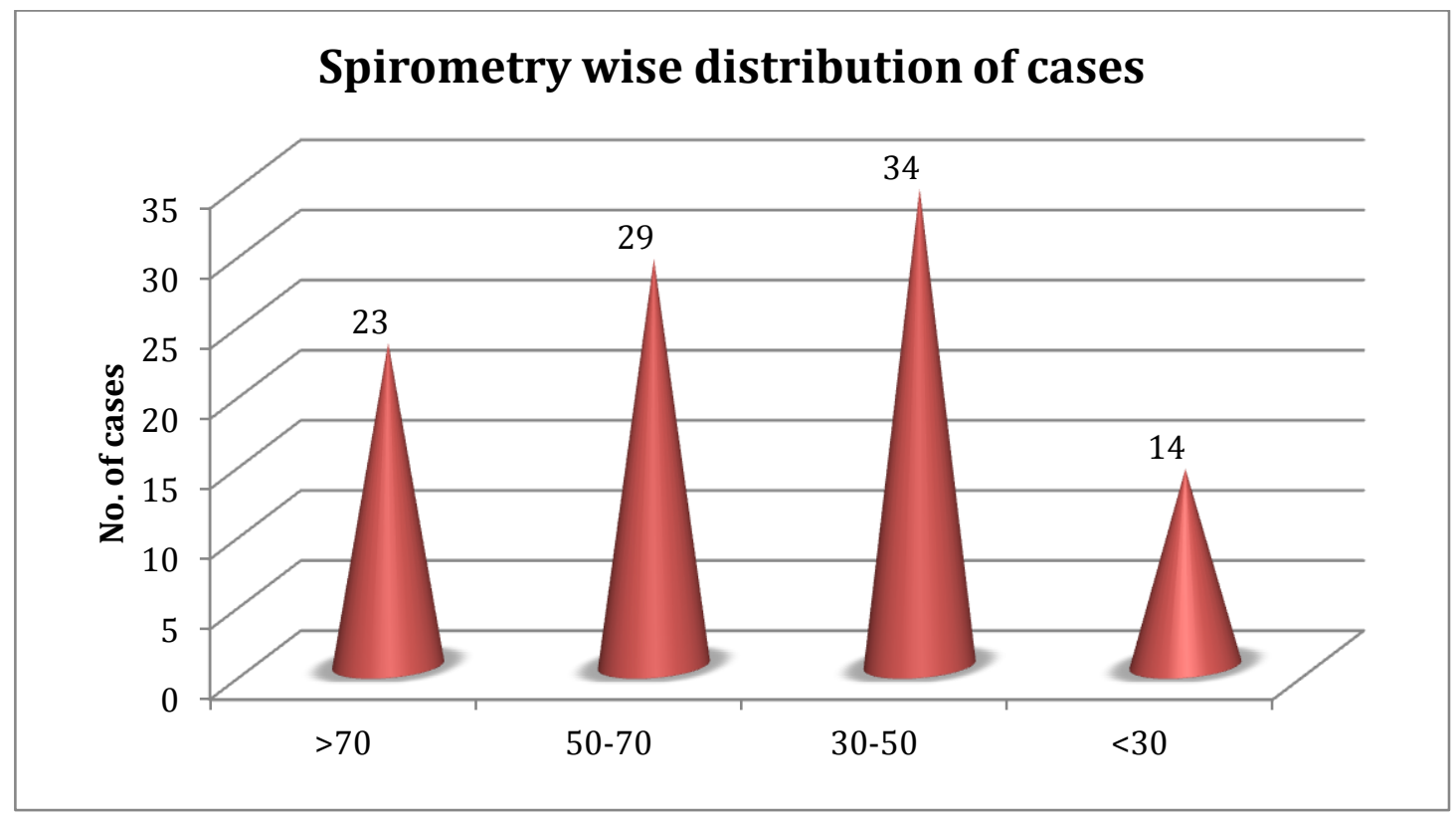

FEV1 level wise distribution of cases

The mean \& \pm SD of FEV1 in the entire study group was $53.3 \pm 18.3$
Spirometric interpretation is done based on four groups according to GINA guidelines.

Around $34 \%$ of patients had, $\mathrm{FEV}_{1}(30-50 \%)$ moderately severe group. 


\section{Discussion}

In this study, Males (57\%) are found to be more commonly affected than Females (43\%). Asthma 37 were male and female 23. In Rhinosinusitis 15 were male and 9 were female. In Asthma+ Rhinosinusitis male patients were 10 and female 6.

According to Dr. S.K. Jindal, et al, total male patients were 54883 and female were 53928, which showed male preponderance which is similar to our study ${ }^{8}$

Male preponderance due to more exposed to allergens in work place, exposed more to pollution than females, smoking habits.

According to this study allergic conditions are common in younger group.which is in contrast to Dr. S.K. Jindal et al, Overall, 31.4\% were aged less than 45 years, and another $59.6 \%$ were aged 45- 74 years. $^{8}$

According to Farida Agha et, al. undertook a study to estimate the serum $\operatorname{IgE}$ levels were estimated in 219 patients with various allergic disorders in which higher levels are found to be in age group of 15-25 years and lowest in >55 years and males had higher IGE levels than females at given age ${ }^{9}$, on par with our study.

In this study total $70 \%$ of Bronchial asthma patients had elevated serum IGE levels. According to study by C. Bachert \& N. Zhang, et al. about $60-80 \%$ of patients with severe asthma are SEIgE-positive, and about one-third of these patients are nonatopic, suggesting that superantigens may be the cause of the so-called intrinsic form of asthma. ${ }^{10}$

Serum IgE levels are found to be elevated in all three categories asthma, rhinosinusitis and asthma+rhinosinusitis but it is more consistently increased in Asthma and Asthma+ Rhinosinusitis.

According to Jarvis D, Newson R, Lotvall J, et al.

20-33\% of patients with chronic rhinosinusitis also have asthma, a prevalence nearly four times greater than that of the general population. ${ }^{11}$

Farida Agha et, al. undertook a study to estimate the serum $\operatorname{IgE}$ levels in with various allergic conditions. Serum IGE levels were estimated in 219 patients with various allergic disorders, average serum IGE levels in ASTHMA is 390IU/ML. ${ }^{9}$ According to this study average serum $\operatorname{IgE}$ levels in asthma patients are in the range of 201-400 IU/L.

According to Lynn e katz et, Al. $\geq 150 / \mu 1$ of AEC was noted in $85 \%$ of asthma patients. ${ }^{12}$ In this study Absolute eosinophil count is raised in 65\% of asthma patients and $37.5 \%$ in Rhinosinusitis patients whereas combination of both rhinosinusitis and asthma patients shows $68.75 \%$. Blood eosinophilia and the extent of eosinophilic inflammation is related to the severity of nasal disease.

\section{Conclusion}

- Atopy should be assessed by measuring Absolute eosinophil count and serum $\operatorname{IgE}$ Levels in all allergic conditions.

- Increased levels of $\mathrm{IgE}$ is associated with severe form of allergy which is difficult to control.

- In this study elevated eosinophils and $\operatorname{IgE}$ are common in males and in younger patients of asthma, allergic rhinitis \& rhinosinusitis.

- $70 \%$ of Asthma patients had increased IgE levels\& $65 \%$ had increased AEC.

- $33 \%$ had normal IgE levels \& $44 \%$ had normal AEC levels suggesting non atopic cause of disease.

- We suggest assessment of FEV1 in all patient of allergic rhinitis and rhinosinusitis.

- Specific tests like specific IgE and skin prick test should be done to know the specific allergen causing the disease.

- In conditions with high IGE Levels newer modalities of treatment like immunotherapy and anti-IGE like Omalizumab should be considered. 


\section{References}

1. Pawankar R, Canonica GW, ST Holgate ST, Lockey RF, Blaiss M. The WAO White Book on Allergy (Update. 2013).

2. Global Initiation of Asthma (GINA 2017update).

3. Fokkens W, Lund V, Bachert C, Clement P, Hellings P, Holmstrom M, et al. EAACI position paper on rhinosinusitis and nasal polyps. Allergy 2005;60:583-601.

4. Van Zele T, Claeys S, Gevaert P, Van Maele G, Holtappels G, Van Cauwenberge $\mathrm{P}$, et al. Differentiation of chronic sinus diseases by measurement of inflammatory markers. Allergy 2006;61:1280-9.

5. Johansson $\mathrm{SG}$, Bieber $\mathrm{T}$, Dahl R, Friedmann PS, Lanier BQ, Lockey RF, et al. Revised nomenclature for allergy for global use: Report of the Nomenclature Review Committee of the World Allergy Organization, October 2003. J Allergy Clin Immunol 2004;113:832- 6.

6. Annesi-Maesano I. Epidemiological evidence of the occurrence of rhinitis and sinusitis in asthmatics. Allergy 1999;54 (Suppl 57):7-13.

7. Slavin RG, Sinusitis in adults and its relation to allergic rhi- nitis, asthma and nasal polyps. J All Clin Immunol 1988;82: 950-6.

8. Dr. S. K. Jindal; Indian Study on Epidemiology of Asthma, Respiratory Symptoms and Chronic Bronchitis (INSEARCH) A Multi-Centre Study (2006- 2009)

9. Farida Agha, Agha Sadaruddin, S. Mohsin Ali (PMRC Central Research Centre, Islamabad. Serum IgE Levels in Patients with Allergic Problems and Healthy Subjects Pages with reference to book, From 166 To 169.
10. Bachert \& N. Zhang; Chronic rhinosinusitis and asthma: novel understanding of the role of IgE 'above atopy' doi: 10.1111/j.1365-2796.2012.02559.

11. Jarvis D, Newson R, Lotvall $\mathrm{J}$, et al. Asthma in adults and its associ- ation with chronic rhinosinusitis: The GA2LEN survey in Europe. Allergy 67:91-98, 2012. 28

12. Lynn E. Katz Blood Eosinophil Count Is a Useful Biomarker to Identify Patients with Severe Eosinophilic Asthma February 15,2014 . 